\title{
Cutaneous Verruciform Xanthoma
}

National Cancer Institute

\section{Source}

National Cancer Institute. Cutaneous Verruciform Xanthoma. NCI Thesaurus. Code C4478.

A rare, benign wart-like skin lesion of unknown etiology that is usually found in the genital or perianal area and consists of hyperkeratosis and aggregates of foam cell macrophages. 